Check for updates

Cite this: RSC Adv., 2018, 8, 25236

\title{
Influence of L-lysine on the permeation and antifouling performance of polyamide thin film composite reverse osmosis membranes
}

\author{
Ruizhang Xu, (D) Guan Xu, Jiantao Wang, Jinyao Chen, (D) Feng Yang, Jian Kang (D) * \\ and Ming Xiang
}

Polyamide thin film composite (TFC) reverse osmosis (RO) membranes were prepared in this study. L-Lysine is used as a type of aqueous additive during interfacial polymerization. As a result, the pure water flux (PWF) of the resulting membranes increased by around $18 \%$ and their salt rejection improved from $98.17 \%$ to $98.40 \%$ at an optimum L-lysine dosage of $0.1 \mathrm{wt} \%$. Additionally, the anti-fouling properties of the resulting membranes were enhanced. The chemical structure of the membranes was investigated using attenuated total reflectance Fourier transform infrared (ATR-FTIR) spectroscopy and X-ray photoelectron spectroscopy (XPS). The morphologies of the top surface and cross-section of the membranes were revealed by scanning electron microscopy (SEM), transmission electron microscopy (TEM) and atomic force microscopy (AFM). Furthermore, contact angle (CA) and zeta potential measurements were carried out to determine the surface properties of the membranes. The results showed that the TFC RO membrane became thinner, smoother, smaller in surface area, more hydrophilic and more negatively charged after the introduction of L-lysine. Accordingly, the reason for the enhancement in the PWF and anti-fouling properties of the TFC RO membranes with the introduction of L-lysine was analyzed. The thinner selective layer (increase in concentration gradient across the membrane) with carboxyl groups (hydrogen bond interactions) and loose structure (greater free volume and sub-nanometer pores) resulted in low hydraulic resistance to the permeability of the polyamide selective layer, which led to the enhancement in PWF. Also, the smoother and more hydrophilic top surface and the increase in negative charges in the selective layer contribute to the improvement in anti-fouling property.

Received 14th March 2018
Accepted 3rd July 2018
DOI: $10.1039 /$ c8ra02234h
rsc.li/rsc-advances

\section{Introduction}

Currently, the most crucial problem for human beings is the global water crisis. Accordingly, reverse osmosis (RO) technology, which desalinates sea water or brackish water using a reverse osmosis membrane, is the most widely accepted desalination technology.

In 1959, at the University of Florida, C. E. Reid and E. J. Breton demonstrated the first reverse osmosis (RO) membrane by the phase-separation of cellulose acetate; ${ }^{1}$ however, this type of symmetric dense membrane exhibited low permeate flow. Subsequently, in 1960, Sidney Loeb and Srinivasa Sourirajan at UCLA prepared the first practical RO membrane (asymmetric cellulose acetate membrane), and the asymmetric structure of their membrane resulted in a significant improvement in flux (10 times larger than that of Reid and Breton's membranes), which made cellulose acetate membranes commercially viabile. ${ }^{2}$ In 1980, a fully aromatic interfacial composite membrane was

State Key Laboratory of Polymer Materials Engineering, Polymer Research Institute of Sichuan University, Chengdu 610065, People's Republic of China.E-mail: jiankang@ scu.edu.cn; Fax: +86-028-8540 6578; Tel: +86-028-8540 6333 developed by John Cadotte. To obtain this type of membrane, phenylene diamine and trimesoyl chloride were chosen as monomers to react via thin-film composite (TFC) technology, ${ }^{3}$ which involves manufacturing a thin polyamide selective layer on a support layer (an ultrafiltration membrane) through an interfacial polymerization method. This type of membrane showed both high flux and high salt rejection properties, became the new industry standard and was widely used in the industrial desalination of seawater and brackish water. ${ }^{4-11}$

Currently, cross-linked aromatic polyamide reverse osmosis (RO) membranes prepared through the interfacial polymerization method using aromatic diamines (e.g. m-phenylenediamine (MPD)) and aromatic acyl chlorides (e.g. trimesoyl chloride (TMC)) show the best commercial value. ${ }^{12}$ Specifically, the aromatic diamine in aqueous solution reacts with the aromatic acyl chloride in organic solution on the top surface of the ultrafiltration membrane support (e.g. polysulfone asymmetric membrane), which provides mechanical support for the polyamide selective layer. ${ }^{12-14}$ To date, most commercial TFC RO membranes are based on polyamide TFC films. ${ }^{15}$

However, TFC membranes face many problems in practical application, including a trade-off between water flux and salt 
rejection, anti-fouling property, chlorine tolerance, anti-microbial property, and life span. Thus, numerous efforts have been made to optimize the performance of TFC membrane.

To enhance the water permeability of TFC membranes, significant related research has been developed, and the main ideas or solutions include (a) synthesis or design of new selective layers using new monomers and (b) modifying the selective layer by physical/chemical methods.

The first method is difficult to perform, but the latter is easily conducted. The introduction of hydrophilic materials (such as 1,3-diamino-2-hydroxypropane ${ }^{16}$ and $m$-phenylenediamine-5sulfonic acid ${ }^{17}$ ) and polymers with bulky groups (such as triamine 3,5-diamino- $N$-(4-aminophenyl) benzamide $^{\mathbf{1 8}}$ and bisphenol $\mathrm{A}^{\mathbf{1 9}}$ ) or flexible main chains into the polyamide selective layer by chemical modification is an efficient way to optimize the membrane flux.

Perera et $a l .{ }^{16}$ used 1,3-diamino-2-hydroxypropane (DAHP) to partially replace MPD during interfacial polymerization, and the flux of the resulting membranes improved by around $22 \%$ while maintaining the same level of salt rejection. Zhou Yong et al. ${ }^{17}$ adopted $m$-phenylenediamine-5-sulfonic acid (SMPD) as an additive in the aqueous phase to introduce hydrophilic sulfonic acid into the polyamide selective layer, and the results showed that the flux of the RO membrane increased significantly, but its $\mathrm{NaCl}$ rejection decreased. Ahmad et al. ${ }^{20}$ used 3,5diaminobenzoic acid (BA) during interfacial polymerization to introduce carboxylic acid groups in the selective layer, leading to the improvement in the permeability of the polyamide selective layer. In addition, the introduction of various polymers into aromatic polyamides such as poly(vinyl phenol) (PVP) and poly(vinyl alcohol) (PVA) with bulky groups or flexible main chains is also an effective way to obtain enhanced performances such as enhanced water permeability. ${ }^{21}$ DMSO was added to the aqueous phase as an additive during interfacial polymerization, ${ }^{22,23}$ and the number and size of network pores or aggregate pores in the polyamide matrix as well as the surface roughness increased significantly, resulting in a notable enhancement in flux; however, a considerable and decrease in salt rejection was observed simultaneously.

Membrane fouling is a frequent phenomenon during the application of the RO method, which always leads to a decrease in water output and quality. Commonly, to remove the fouling on the surface of membranes, periodic cleaning of the membrane and pretreatment of the feed water are necessary, which are always expensive and cannot solve the fouling problem completely. Therefore, the development of anti-fouling membranes is attractive and meaningful to the desalination industry. To date, surface modification is considered the most efficient way to increase the anti-fouling property, and is based on increasing the surface hydrophilicity and surface smoothness of the membrane. Grafting hydrophilic polymers such as PVA and PEG onto the surface of membranes can significantly enhance their anti-fouling performance; ${ }^{\mathbf{2 4 , 2 5}}$ however, a decrease in flux cannot be avoided because of the resistance of the additional layer. Therefore, the development of membranes with good anti-fouling property without sacrificing membrane flux is a promising research direction.
L-Lysine is an $\alpha$-amino acid that can form proteins through the biosynthesis process. It is a hydrophilic and biocompatible material with a flexible main chain. Its molecular formula is similar to MPD and similar to the MPD molecule after a ringopen reaction, its linear monomer demonstrates better hydrophilic properties compared with its aromatic counterpart, ${ }^{\mathbf{1 6}}$ and the carboxyl group in L-lysine indicates higher hydrophilicity. Furthermore, the low cost of L-lysine indicates that it can be used as an industrial additive. In a previous study, L-lysine was used as an additive in a selective membrane polymerized with piperazine (PIP) and trimesoyl chloride (TMC) for recognizing enantiomers. ${ }^{22,26}$

In our research, L-lysine was used as an additive to MPD to increase the final permeability of polyamide TFC RO membranes because its units add flexible molecular chains to the rigid aromatic polyamide structure, thus improving the chain mobility of polyamides and consequently increasing the water permeability.

The carboxyl group in L-lysine is expected to contribute additional hydrophilicity to the polyamide network ${ }^{20}$ because of the hydrogen bond interaction between the carboxyl group and water molecule. In addition, Freger ${ }^{27}$ reported that the polyamide selective layer comprises a bilayer structure with an external negative electronic layer and intermediate positive electronic layer. Thus, it is assumed that the polyamide TFC membrane is a type of weakened charged mosaic membrane. Charged mosaic membranes with special transport properties $^{28-30}$ are frequently used in the piezodialysis desalination field. ${ }^{28}$ It contains equivalent amounts of cationic and anionic groups in the membrane matrix that can accelerate salt permeation. ${ }^{31}$ Inspired by this, the introduction of an appropriate amount of L-lysine during interfacial polymerization is also expected to afford anionic carboxyl groups in the polyamide matrix, thus increasing the electric charge effect of the polyamide selective layer and weakening the salt permeation (improved salt rejection).

Colloidal fouling is a common fouling issue, which widely exists in natural waters. Colloidal fouling has negative charges, same as the carboxyl group from L-lysine; thus, the introduction of L-lysine is expected to improve the colloidal fouling resistance by both electrostatic repulsion and increasing the hydrophilicity of the membrane matrix. ${ }^{32}$

In this study, L-lysine was added to the aqueous solution during interfacial polymerization; to the best of our knowledge, this method has not been reported to date. As shown in Fig. 1, the L-lysine unit can be incorporated into the polyamide network because the amino group $\left(-\mathrm{NH}_{2}\right)$ in $\mathrm{L}$-lysine can react with the chloride group $(-\mathrm{COCl})$ in TMC. The effects of $\mathrm{L}$-lysine on the flux and rejection properties, chemical structure, morphology, and hydrophilicity of the polyamide selective layer were investigated.

\section{Materials and methods}

\subsection{Materials}

Polysulfone (PSf) with an average molecular weight of $22000 \mathrm{~g}$ $\mathrm{mol}^{-1}$ was purchased from Solvay (China). $N, N$ - 


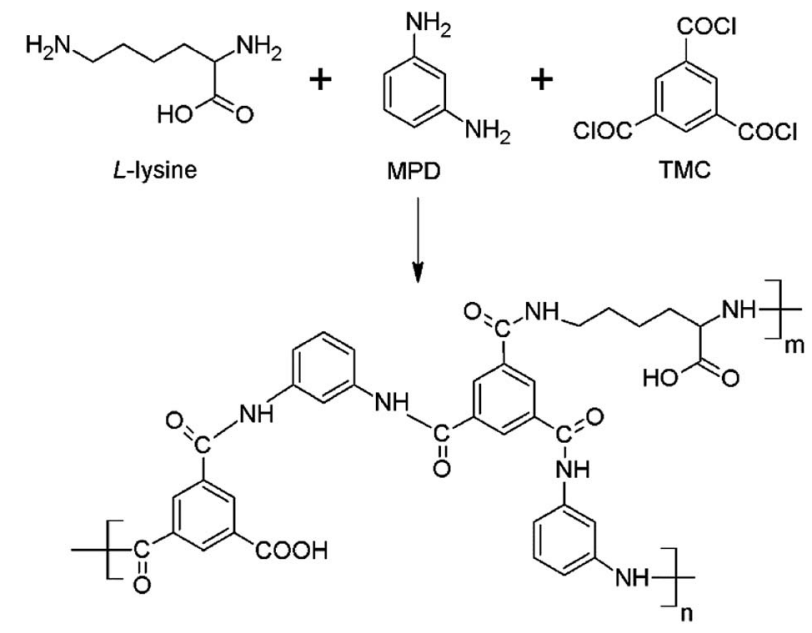

Fig. 1 Chemical structure of the polyamide selective layer from the interfacial polymerization of MPD, L-lysine and TMC.

Dimethylformamide (DMF) (analytical purity of 99.5\%), 1,3,5benzenetricarbonyl trichloride (TMC, 98\%), $m$-phenylenediamine (MPD, 99\%), L-lysine (98\%), hexane (anhydrous, 99\%) and colloidal silica (with a particle size of $7-40 \mathrm{~nm}$ and specific surface area (BET) of $300 \mathrm{~m}^{2} \mathrm{~g}^{-1}$ ) were purchased from Aldrich (China).

\subsection{Membrane preparation}

Polysulfone (PSf) support layers (ultrafiltration membrane) for the polyamide selective layers were fabricated by us through the phase separation method. ${ }^{33}$ Briefly, PSf was dissolved in DMF with a constant weight ratio of $18: 82$ (PSf : DMF) to form the casting solution. Then, the casting solution was cast uniformly on a polyester film back layer with a $250 \mu \mathrm{m}$ gap using a handcasting knife. Finally, the casting solution was immersed in a non-solvent (distilled water) bath $\left(25{ }^{\circ} \mathrm{C}\right)$ immediately and rapidly to complete the phase separation process. The asymmetric PSf support layers were stored in distilled water until use.

Polyamide selective layers were synthesized on the PSf support layers by interfacial polymerization. Briefly, the support layer was clamped between a glass plate and a Teflon frame and the surface of PSf support layer was thoroughly dried using a high pressure nitrogen air-knife. Then, the MPD/L-lysine aqueous solution was poured on the surface of the support layer and left undisturbed for $3 \mathrm{~min}$.

Then the excess aqueous solution was removed and the residual liquid was wiped off with a high pressure nitrogen airknife. Subsequently, TMC hexane solution was poured on the surface of the support layer and the reaction was allowed to proceed for $30 \mathrm{~s}$. Finally, the remaining organic solution was removed. A rhodamine B aqueous solution $\left(500 \mathrm{mg} \mathrm{L}^{-1}\right)$ was sprayed on the resulting membrane surface to make the significant defects visible, which preferentially stained PSf red if any region was not covered completely by polyamide. ${ }^{34}$ The resulting membrane was stored in distilled water before testing. This synthesis process did not include the use of common additives such as camphor sulfonic acid (CSA), sodium dodecyl sulfate (SDS) and triethylamine (TEA), and no post-treatment such as a curing process was adopted.

The concentration of MPD and L-lysine in aqueous solution and the concentration of TMC in organic (hexane) solution are shown in Table 1. In this study, all the samples were named L- $X$, where $X$ corresponds to the $\mathrm{L}$-lysine dosage $(\mathrm{w} / \mathrm{v} \%)$.

\subsection{Diffusion kinetics}

Ultraviolet-visible spectroscopy (TU-1900, PERSEE, China) was adopted to research the diffusion kinetics of MPD in hexane under the influence of L-lysine. First, $1.0 \mathrm{~mL}$ of aqueous solution (MPD: $2.0 \%$ and L-lysine: $0 \%, 0.1 \%, 0.3 \%$ and $0.5 \%$ ) was added to a cuvette carefully using a micro-syringe. The liquid and air interface was below the light source. Then, $2.0 \mathrm{~mL}$ pure hexane was added to the cuvette immediately with a microsyringe and the UV absorption spectrum was recorded simultaneously. The diffusion process was allowed for $10 \mathrm{~min}$. The L-lysine aqueous solution shows no distinct absorption peak via UV-vis spectroscopy, while MPD has two absorption bands, the K band (240 $\mathrm{nm}$ ) and $\mathrm{B}$ band $(288 \mathrm{~nm})$, in the ultraviolet region. According to the Beer-Lambert law, the concentration of MPD in hexane was measured by UV-vis spectroscopy using the absorbance at a wavelength of $288 \mathrm{~nm} . .^{35,36}$

\section{4. $\mathrm{pH}$ value}

$\mathrm{pH}$ value does significantly influence the interfacial polymerization process. The $\mathrm{pH}$ values of the aqueous solutions were tested using a pH meter (PHS-3Cb, Shanghai Yueping, China) to investigate whether the addition of $\mathrm{L}$-lysine changed the $\mathrm{pH}$ value of the aqueous solutions.

\subsection{Chemical structure characterization}

Fourier transform infrared spectroscopy (FTIR, Nicolet is 50 FTIR, Thermo Fisher Scientific, USA) was adopted to determine the chemical structure of the polyamide selective layer using the ATR (attenuated total reflectance) method. The top surface of the L-0, L-0.3 and L-0.5 samples was tested in our research. Transmittance spectra were recorded in the wavelength range of 650 to $4000 \mathrm{~cm}^{-1}$. To prove that the L-lysine reacts with TMC via interfacial polymerization, $2 \%$ L-lysine aqueous solution was selected to replace the MPD aqueous solution and the resulting membrane was also examined by ATR-FTIR.

Table 1 Concentration of the aqueous and organic solutions for interfacial polymerization

\begin{tabular}{|c|c|c|c|}
\hline \multirow[b]{2}{*}{ Sample } & \multicolumn{2}{|c|}{$\begin{array}{l}\text { Aqueous solution } \\
(\mathrm{w} / \mathrm{v} \%)\end{array}$} & \multirow{2}{*}{$\begin{array}{l}\text { Organic solution } \\
(\mathrm{w} / \mathrm{v} \%) \\
\text { TMC }\end{array}$} \\
\hline & MPD & L-Lysine & \\
\hline L-0 & 2.0 & 0 & 0.1 \\
\hline L-0.05 & 2.0 & 0.05 & 0.1 \\
\hline L-0.1 & 2.0 & 0.1 & 0.1 \\
\hline L-0.2 & 2.0 & 0.2 & 0.1 \\
\hline L-0.3 & 2.0 & 0.3 & 0.1 \\
\hline L-0.4 & 2.0 & 0.4 & 0.1 \\
\hline L-0.5 & 2.0 & 0.5 & 0.1 \\
\hline
\end{tabular}


The surface elements were analyzed by X-ray photoelectron spectroscopy (XPS) (Axis Ultra DLD, Kratos Analytical, UK). Elements $\mathrm{C}, \mathrm{N}$ and $\mathrm{O}$ were of interest in our research. The results were analyzed using the Casa software.

Since the polyamide backbone comprises linear parts and cross-linked parts, the cross-linking degree $(X)$ can be calculated using the following formulae: ${ }^{23,37}$

$$
\begin{aligned}
& m+n=1 \\
& \frac{\mathrm{N}}{\mathrm{O}}=\frac{3 m+2 n}{3 m+4 n}
\end{aligned}
$$

where $\mathrm{N}$ and $\mathrm{O}$ are the nitrogen and oxygen element concentrations measured by XPS, respectively, $m$ is the ratio of the cross-linking part and $n$ is the ratio of the linear part in the polyamide.

\subsection{Morphology (SEM, TEM and AFM)}

The morphologies of the top surface and cross-section of the polyamide selective layers were observed via scanning electron microscopy (SEM, Inspect F, FEI, USA). The morphology of the cross-section of the polyamide selective layer was observed via transmission electron microscopy (TEM, Tecnai G2 F20, FEI, USA).

The surface roughness of the polyamide selective layers was tested using atomic force microscopy (AFM) (Asylum Research MFP-3D microscope, Oxford Instruments, UK) in tapping mode, where an area of $5 \mu \mathrm{m} \times 5 \mu \mathrm{m}$ was scanned for each sample.

The quantitative analysis of surface roughness is denoted as the maximum peak-to-valley distance $\left(R_{\mathrm{p}-\mathrm{v}}\right)$, average roughness $\left(R_{\text {avg }}\right)$, root-mean-squared roughness $\left(R_{\text {rms }}\right)$ and surface area $(S) .{ }^{38}$ Before SEM and AFM testing, all the samples were dried completely in a vacuum oven.

\subsection{Surface properties}

The contact angle (CA) of the polyamide selective layers were determined using a contact angle instrument (K100, KRÜSS, Germany) to obtain their hydrophilic properties. A $4 \mu \mathrm{L}$ water droplet was placed on the top surface of each sample. Then, the contact angle (CA) of the droplet with the membrane's surface was measured. At least 5 repeated trials were performed on each polyamide selective layer.

Zeta potential was measured using an Anton Paar SurPASS Electrokinetic Analyzer (Anton Paar, US) and $1 \mathrm{mM} \mathrm{KCl}$ solution was used as the background electrolyte for all the tests. The $\mathrm{pH}$ value ranged from 4.0 to 10.0 , and all tests were conducted at $25{ }^{\circ} \mathrm{C}$.

\subsection{Pure water flux (PWF) and rejection measurements}

The PWF measurement was performed using a cross-flow flat membrane filtration experimental instrument (FlowMen0021HP, FMT, China). PWF was calculated using the following formula:

$$
\mathrm{PWF}=\frac{V}{A \times t}
$$

where PWF $\left(\mathrm{L} \mathrm{m}^{-2} \mathrm{~h}^{-1}\right)$ is the flux of pure water, $V(\mathrm{~L})$ is the permeate volume, $A\left(\mathrm{~m}^{2}\right)$ is the permeate area of the membrane, and $t(\mathrm{~h})$ is the sampling time.

The salt rejection $(R)$ of each sample was tested by permeating a feed solution containing $2000 \mathrm{ppm} \mathrm{NaCl}$, and the conductivity of the permeate solution (denoted as $C_{\mathrm{p}}$ ) and feed solution (denoted as $C_{\mathrm{f}}$ ) were measured using a conductivity tester (DDS-11A, Shanghai Yueping, China).

The salt rejection $(R)$ can be obtained using the following formula:

$$
R=\left(1-\frac{C_{\mathrm{p}}}{C_{\mathrm{f}}}\right)
$$

The PWF and salt rejection measurements were performed at $20 \pm 0.1{ }^{\circ} \mathrm{C}$ with a transmembrane pressure of $1.6 \mathrm{MPa}$ and water flow rate of 7 LPM (litre per minute). To ensure data accuracy and repeatability, 5 valid tests were performed for each membrane.

Intrinsic membrane resistance $\left(R_{\mathrm{m}}\right)$ can be used to manifest the structural properties of the polyamide layer, ${ }^{37}$ and PWF is related to the feed pressure $(P)$ as follows:

$$
\mathrm{PWF}=P /\left(\mu R_{\mathrm{m}}\right)
$$

where, $\mu$ denotes the dynamic viscosity of water. In our research, the feed pressure of 8-24 bar was used, and $R_{\mathrm{m}}$ was also calculated. A low $R_{\mathrm{m}}$ value suggests the optimal balance between the thickness, crosslinking density, and surface area of a polyamide layer.

\subsection{Fouling experiments}

The fouling experiments were conducted in a cross-flow flat membrane filtration experimental instrument (FlowMen0021HP, FMT, China) (see Section 2.3). Colloidal silica was chosen as the model foulant. Before testing, the membrane samples were washed with distilled water for at least $2 \mathrm{~h}$. In the testing process, each sample was tested by permeating a feed solution containing 500 ppm colloidal silica, and all experiments were performed at $20 \pm 0.1{ }^{\circ} \mathrm{C}$ with a transmembrane pressure of 1.6 MPa and water flow rate of 4 LPM (litre per minute). The flux of the samples during the fouling experiments was tested and recorded every $10 \mathrm{~min}$. The retentate was fed back to the tank to maintain a stable concentration of colloidal silica.

Subsequently, the flux recovery ability of each sample was determined. First, the membranes were washed with distilled water under vigorous stirring for around $30 \mathrm{~min}$. Then, the water flux of the membranes was tested using distilled water under the same conditions as described in Section 2.3.

The anti-fouling property was quantitatively analyzed, and the total flux decline ratio $\left(D_{t}\right)$ and flux recovery ratio (FRR) were calculated as follows:

$$
\mathrm{DR}_{\mathrm{t}}=\frac{f_{1}-f_{\Delta}}{f_{1}} \times 100 \%
$$




$$
\operatorname{FRR}=\frac{f_{2}}{f_{1}} \times 100 \%
$$

where $f_{1}$ is the pure water flux of each sample, $f_{\Delta}$ is the flux of each sample after testing under foulant feed solutions for $10 \mathrm{~h}$, and $f_{2}$ is the recovery water flux.

\section{Results and discussion}

\subsection{Diffusion kinetics}

The MPD absorbance at $288 \mathrm{~nm}$ versus time is shown in Fig. 2. The result shows that under the participation of L-lysine, the absorbance of MPD becomes weak, which indicates a lower concentration of MPD in the organic phase. This suggests that $\mathrm{L}-$ lysine can reduce the diffusion rate of MPD from the aqueous phase into the organic phase. Moreover, the higher the concentration of L-lysine in the aqueous phase, the slower would be the diffusion rate of MPD into the organic phase. The reason for L-lysine decreasing the diffusion rate of MPD may be attributed to the formation of ion pairs between MPD and $\mathrm{L}^{-}$ lysine. The hydrophilic nature of $\mathrm{L}$-lysine hinders the diffusion rate of ion pairs in the aqueous-organic interface, which results in a thinner reaction zone for interfacial polymerization and consequently a thinner selective layer. The thickness of the resulting polyamide TFC membrane was examined by ARFFTIR, SEM and TEM (see Sections 3.3 and 3.4).

\section{2. $\mathrm{pH}$ value of the aqueous solutions}

The existence of carboxyl groups in the L-lysine chain may cause its aqueous solution to become acidic. It is well known that the process of interfacial polymerization produces $\mathrm{HCl}$, which comes as the byproduct of the reaction between $-\mathrm{NH}_{2}$ and $-\mathrm{COCl}$. Thus, the acidic solution hinders the process of interfacial polymerization. The $\mathrm{pH}$ values of the $\mathrm{L}-\mathrm{lysine}$ solution $(2.0 \%)$ and $\mathrm{MPD} / \mathrm{L}^{-}$ lysine aqueous solutions were tested and the results are listed in Table 2. From the results, it can be inferred that the L-lysine solution is weakly alkaline, and the MPD/L-lysine aqueous

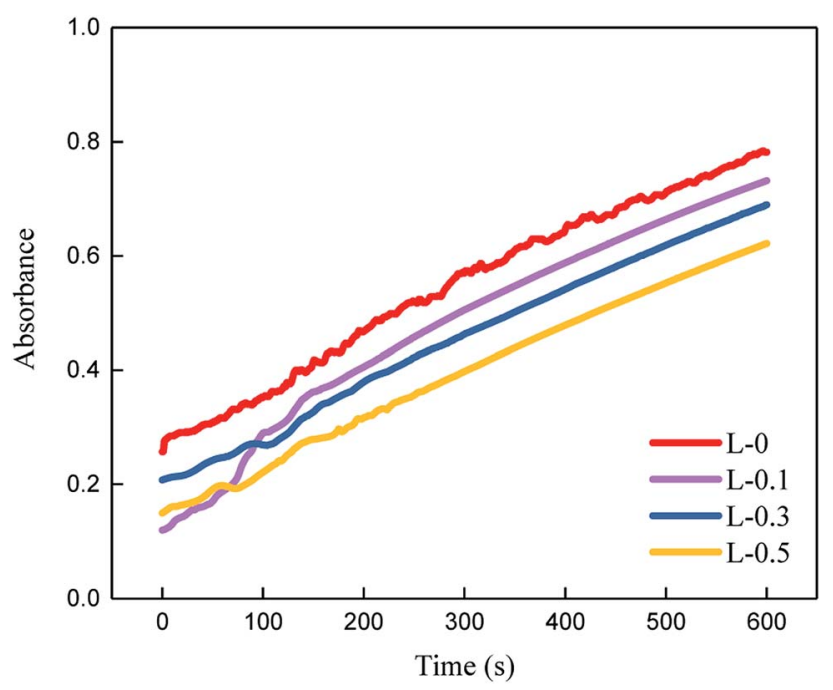

Fig. 2 Diffusion rate of MPD estimated by measuring the absorbance at $288 \mathrm{~nm}$.
Table $2 \mathrm{pH}$ values of the L-lysine aqueous solution and MPD/L-lysine aqueous solutions

\begin{tabular}{ll}
\hline Sample & pH value \\
\hline L-Lysine (2\%) & 9.84 \\
L-0 & 9.53 \\
L-0.1 & 9.70 \\
L-0.3 & 9.73 \\
L-0.5 & 9.74 \\
\hline
\end{tabular}

solutions have a slightly higher $\mathrm{pH}$ than the MPD solution. Therefore, we conclude that the introduction of $\mathrm{L}$-lysine does not influence the $\mathrm{pH}$ value of the MPD/L-lysine aqueous solution as well as the process of interfacial polymerization.

\subsection{Chemical structure of the polyamide selective layer}

ATR-FTIR was adopted to determine the chemical structure of the polyamide selective layer. ATR-FTIR radiation penetrated the sample; thus, signals from the PSf support layer can also be seen in the ATR-FTIR spectra. Specifically, the ATR-FTIR spectra of the samples consist of bands from both the polysulfone support layer and polyamide selective layer, which are shown in Fig. 3.

Fig. 3(a) presents the ATR-FTIR spectrum of the resulting membrane from the interfacial polymerization between $\mathrm{L}$-lysine and TMC. The existence of a peak at $1541 \mathrm{~cm}^{-1}$ (corresponding to the stretching vibration of $\mathrm{C}-\mathrm{N}$ and in-plane bending of $\mathrm{N}-\mathrm{H}$ ) suggests the formation of polyamide, indicating that $\mathrm{L}-\mathrm{lysine}$ can react with TMC.

Fig. 3(b) and (c) show the ATR-FTIR spectra of the polyamide TFC membranes. Each ATR-FTIR curve shows four unique bands for polyamide and one unique band for polysulfone, which are 1487, 1541, 1609, 1663 and $1584 \mathrm{~cm}^{-1}$, respectively. The band at $1487 \mathrm{~cm}^{-1}$ can be assigned to aromatic ring stretching. The peak at $1541 \mathrm{~cm}^{-1}$ corresponds to the stretching vibration of $\mathrm{C}-\mathrm{N}$ and in-plane bending of $\mathrm{N}-\mathrm{H}$. The band at $1609 \mathrm{~cm}^{-1}$ is attributed to the polyamide aromatic ring stretching. The band at $1663 \mathrm{~cm}^{-1}$ is ascribed to the $\mathrm{C}=\mathrm{O}$ stretching. The band at $1584 \mathrm{~cm}^{-1}$ is the characteristic band for polysulfone. $^{35}$

In general, the thickness of the PA layer is usually measured by cross-section images taken from SEM or TEM. ${ }^{39}$ However, accurate measurements could be quite challenging because (a) only a tiny region was captured and (b) the edge between the PA and PSf layer was sometimes hard to discern. Accordingly, ATRFTIR spectroscopy can be used to estimate the thickness of the PA layer because the thickness and IR absorbance should be positively correlated (although this has not been strictly proven). ${ }^{40}$ Herein, the peak heights of the peaks at 1663,1609 , 1541 and $1487 \mathrm{~cm}^{-1}$ in the ATR-FTIR spectra were selected to estimate the thickness of the polyamide TFC membrane, and the result is shown in Fig. 4.

From Fig. 4, it can be seen that as the dosage of L-lysine increased, the peak heights of the peaks at 1663, 1609, 1541 and $1487 \mathrm{~cm}^{-1}$ decreased, indicating that an increase in the dosage of L-lysine results in a lower polyamide signal. This result 

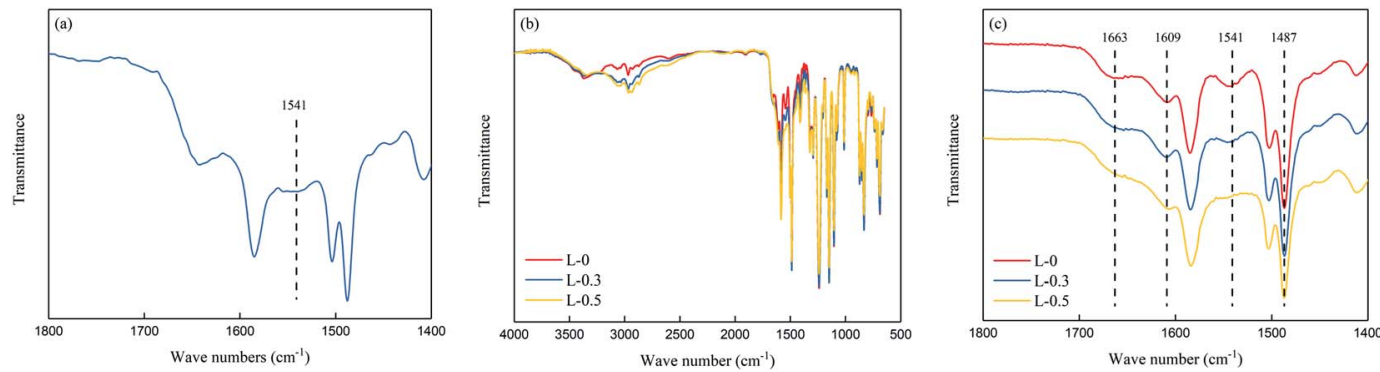

Fig. 3 ATR-FTIR spectra of the polyamide TFC membranes. (a) L-lysine reacted with TMC, (b) resulting polyamide TFC membranes, and (c) expanded spectra showing the functional group region from $1800 \mathrm{~cm}^{-1}$ to $1400 \mathrm{~cm}^{-1}$.

suggests that a thinner polyamide layer was formed on the top surface of the PSf support layer after the addition of L-lysine.

XPS experiment was conducted to reveal the chemical structure and network structure (cross-linking degree) of the polyamide TFC membrane. The XPS spectra are shown in Fig. 5 . Furthermore, the relative atomic concentrations and crosslinking degree of the polyamide TFC membranes were calculated and presented in Table 3.

From the results above, it can be inferred that the addition of L-lysine can change the element concentrations of $\mathrm{C}, \mathrm{N}$ and $\mathrm{O}$ as well as the cross-linking degree of each polyamide TFC membrane. For the membrane prepared using neat MPD and TMC, the cross-linking degree was $78.1 \%$. When $\mathrm{L}$-lysine was added, the cross-linking degree decreased with an increase in Llysine dosage. Hence, the network structure changed due to the effect of L-lysine. A loose inner structure and bigger inner subnanometer pores in the polyamide matrix were obtained because of the addition of L-lysine.

\subsection{Surface morphology of the polyamide selective layer}

The structures and morphologies of the TFC membranes (L-0, L$0.1, \mathrm{~L}-0.3$ and L-0.5) with various $\mathrm{L}-\mathrm{lysine}$ dosages were explored via SEM, TEM and AFM. Fig. 6 shows the morphologies of the top surface and cross-section as well as the surface roughness of the polyamide selective layers measured by SEM, TEM and AFM. The top surface SEM images show the characteristic ridge-and-valley

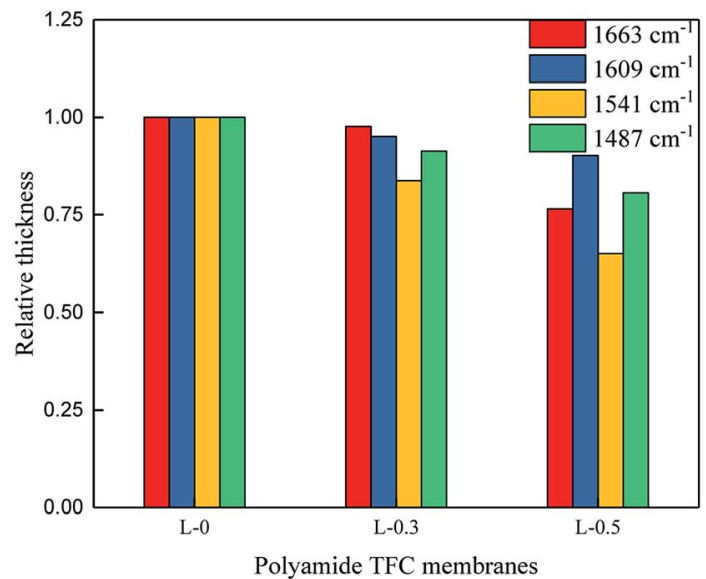

Fig. 4 Relative thickness estimated from the different major absorbance peaks. structure of each membrane. Furthermore, the SEM and TEM images of cross-section show the thickness of each selective layer, and the quantitative analysis from 5 replicate samples, where 10 positions of each sample were measured. The average thickness of the selective layer is presented in Table 4 .

Furthermore, quantitative analysis of the roughness of the surface area was calculated. The values of $R_{\mathrm{p}-\mathrm{v}}, R_{\mathrm{avg}}, R_{\mathrm{rms}}$ and $S$ are calculated by using open-access software Igor pro (6.22A), and the results are listed in Table 4 as well.

From Table 4 and Fig. 6 , it can be seen that the $R_{\mathrm{p}-\mathrm{v}}, R_{\text {avg }}$, $R_{\mathrm{rms}}$, and surface area $(S)$ decrease drastically when L-lysine was added in the aqueous solution. Hence, after the addition of $\mathrm{L}^{-}$ lysine, the surface of the polyamide selective layer became smoother than that of the polyamide selective layer synthesized from neat MPD and TMC.

L-lysine causes a change in surface roughness by affecting the interfacial polymerization process of MPD and TMC because surface roughness is greatly dependent on the monomer type and concentration, where a linear monomer more likely forms a smooth surface under the same experimental conditions. ${ }^{41,42}$

The average thickness of the L-0 polyamide selective layer is $186.9 \mathrm{~nm}$. However, the thickness of the polyamide layer reduces to $147.7 \mathrm{~nm}$ when $0.5 \mathrm{wt} \%$ L-lysine was added. This result is in accordance with the ATR-FTIR result. The decrease in the thickness of the polyamide selective layer may be due to the slow diffusion of aqueous monomer into hexane (organic phase).

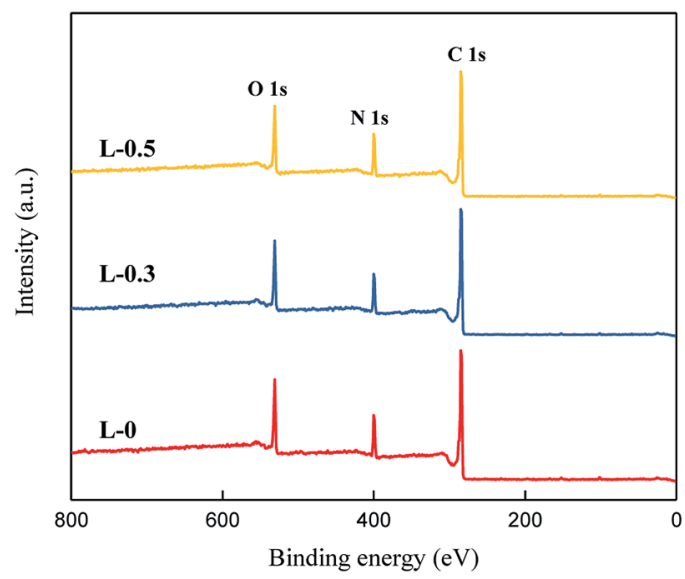

Fig. 5 XPS spectra of the polyamide TFC membranes. 
Table 3 The relative atomic concentrations and cross-linking degrees of the polyamide TFC membranes ${ }^{a}$

\begin{tabular}{llllll}
\hline Sample & $\mathrm{C}$ & $\mathrm{N}$ & $\mathrm{O}$ & $\mathrm{N} / \mathrm{O}$ & $\mathrm{CL} \%$ \\
\hline L-0 & 77.41 & 10.47 & 12.12 & 0.864 & 78.1 \\
L-0.3 & 76.28 & 10.41 & 13.30 & 0.783 & 63.5 \\
L-0.5 & 75.67 & 10.1 & 14.23 & 0.710 & 49.1
\end{tabular}

${ }^{a} \mathrm{CL} \%$ is the cross-linking degree calculated using Formulae (1) and (2).

\subsection{Surface properties}

Generally, a surface with lower contact angle displays better hydrophilicity and greater tendency to be wetted by water. The variation in contact angle (Fig. 7) proves that the existence of $\mathrm{L}^{-}$ lysine increases the hydrophilicity of the polyamide selective layer.

L-0 shows a contact angle of $78.5^{\circ}$, which is typical for aromatic polyamide membranes previously reported..$^{4-45}$ The addition of $\mathrm{L}^{-}$ lysine decreases the contact angle of the polyamide selective layer when the dosage of L-lysine is $0.1 \mathrm{wt} \%$, which suggests that its hydrophilicity is increased. However, when the dosage of L-lysine is more than $0.3 \mathrm{wt} \%$, the contact angle starts to increase slightly.

To explain this finding, we assume that the existence of carboxyl groups in the polyamide network contributes more to the hydrophilic property. On the one hand, due to the hydrogen bond interaction between water molecules and the selective layer, the presence of L-lysine enhances the hydrophilicity and decreases the contact angle. On the other hand, with an increase in the amount of L-lysine, its linear structure makes the selective layer less rough and its surface area smoother. According to the Wenzel model, a smoother hydrophilic surface will lead to an increased contact angle. ${ }^{46}$ Under the combined influence from these two aspects, with the increase in L-lysine content, the contact angle first decreased evidently, and then increased gradually. However, it always remained lower than that of the L-0 sample.

The surface charge of the polyamide TFC membranes was tested in the $\mathrm{pH}$ range of $4.0-10.0$, and the result is illustrated in Fig. 8. The zeta potential decreased with an increase in $\mathrm{pH}$ value. When the $\mathrm{pH}$ value is low, the protonation of $-\mathrm{NH}_{2}$ gives the membrane a positive charge; however, when the $\mathrm{pH}$ value is high, the dissociation of $-\mathrm{COOH}$ causes the membrane to obtain a negative charge. ${ }^{47}$ The addition of L-lysine caused the resulting polyamide TFC membrane to show a more negatively charged property. This phenomenon is mainly due to the existence of a carboxyl group in L-lysine, where a higher dosage of

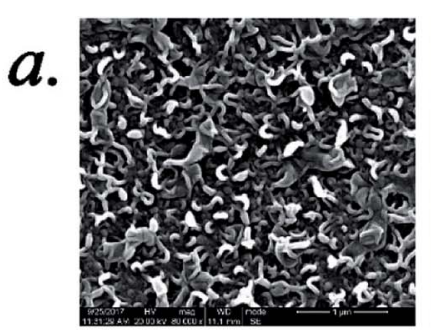

$b$.

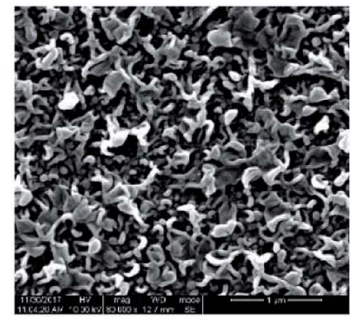

c.
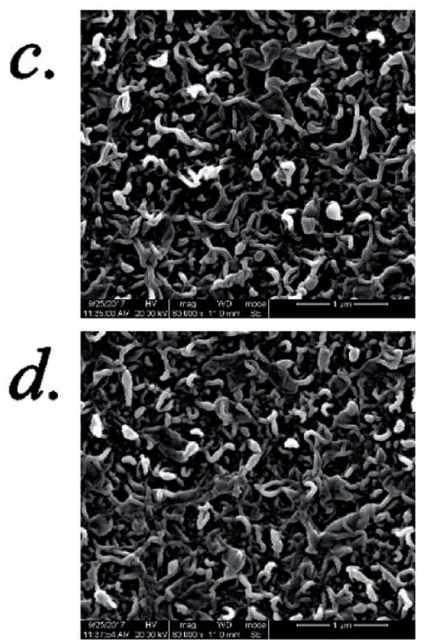
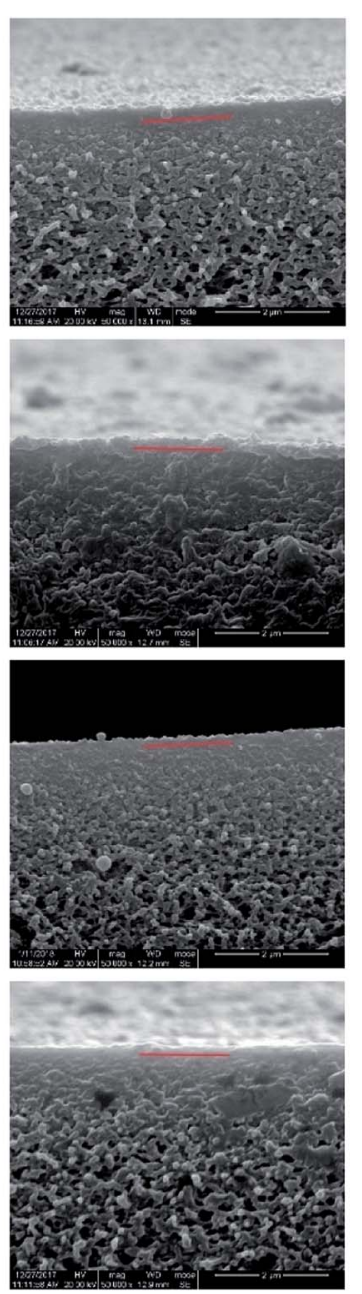
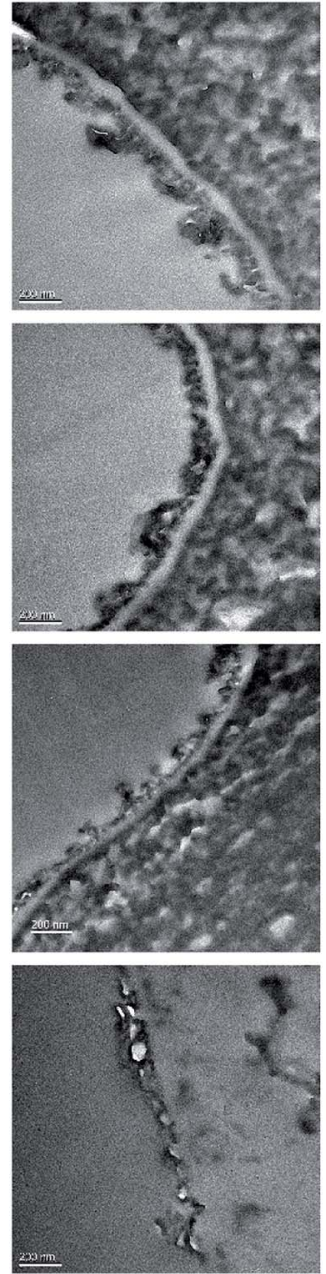
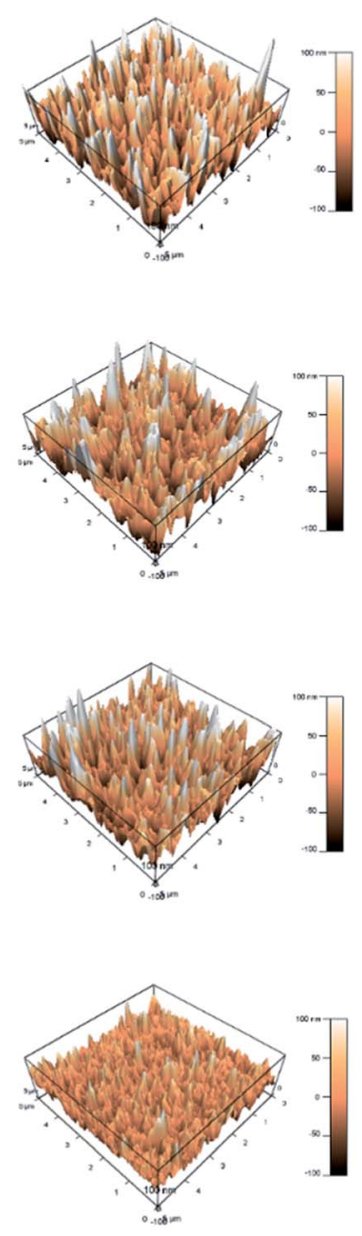

Fig. 6 Structures and morphologies of the TFC membranes with different L-lysine dosages. (a) L-0, (b) L-0.1, (c) L-0.3, and (d) L-0.5. The red line denotes the boundary between the polyamide selective layer and PSf support layer. 
Table 4 Thickness and surface roughness analysis of the polyamide selective layer

\begin{tabular}{|c|c|c|c|c|c|}
\hline Sample & $\begin{array}{l}\text { Maximum Peak-to- } \\
\text { Valley } \\
\text { Distance, } R_{\mathrm{p}-\mathrm{v}}(\mathrm{nm})\end{array}$ & \multicolumn{2}{|c|}{ Surface Roughness (nm) } & $\begin{array}{l}\text { Surface } \\
\text { Area, } \\
S\left(\mu \mathrm{m}^{2}\right)\end{array}$ & $\begin{array}{l}\text { Average } \\
\text { Thickness } \\
(\mathrm{nm})\end{array}$ \\
\hline L-0 & 372.10 & 40.49 & 49.82 & 32.4 & 186.9 \\
\hline L-0.1 & 359.00 & 38.56 & 48.52 & 29.5 & 178.5 \\
\hline $\mathrm{L}-0.3$ & 342.94 & 36.34 & 46.45 & 30.3 & 171.6 \\
\hline
\end{tabular}

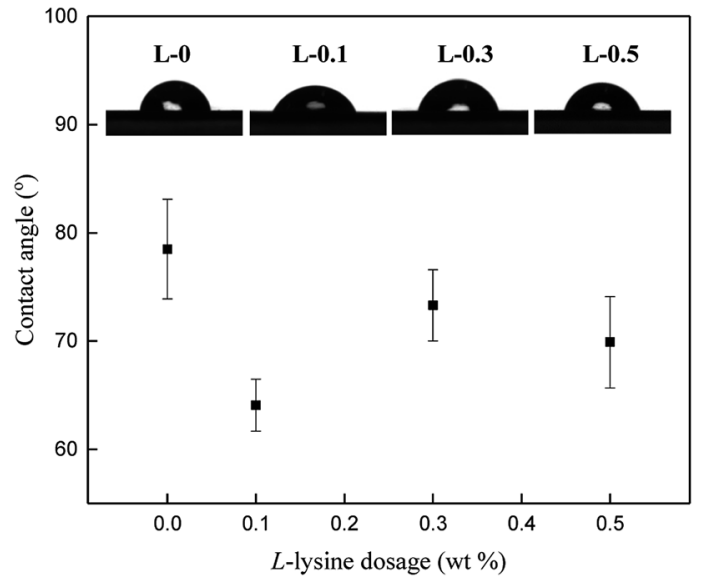

Fig. 7 Contact angle (CA) of the polyamide selective layer with different L-lysine dosages.

L-lysine results in more carboxyl groups in the polyamide matrix, and thus more negative charges. When the dosage of $\mathrm{L}^{-}$ lysine was $0.5 \mathrm{wt} \%$ (L-0.5), the surface charge increased, which may occur because this membrane is thinner than L-0, suggesting less surface negative charge.

\subsection{RO performance of the TFC membranes}

Fig. 9 shows the reverse osmosis performance of the TFC membranes, where the addition of L-lysine evidently influences their permeability. It can be seen that the TFC membrane prepared from pure MPD and TMC (L-0) exhibits a PWF of

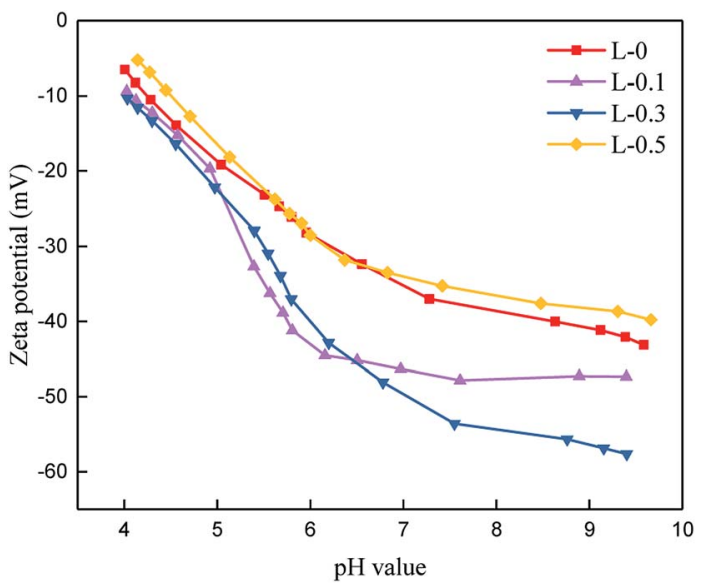

Fig. 8 Zeta potential of the polyamide selective layer.
49.19 $\mathrm{L}\left(\mathrm{m}^{-2} \mathrm{~h}^{-1}\right)$ and salt rejection of $98.17 \%$. When $\mathrm{L}$-lysine was introduced into the polyamide network, the pure water flux increased significantly. When $0.1 \mathrm{wt} \%$ of $\mathrm{L}$-lysine was added (L$0.1)$, the PWF increased to $58.17 \mathrm{~L}\left(\mathrm{~m}^{-2} \mathrm{~h}^{-1}\right)$ and salt rejection increased to around $98.40 \%$. Compared with original L-0, the flux of the L-0.1 membrane increased by $18 \%$ and its salt rejection also slightly increased from $98.17 \%$ to $98.40 \%$. With the continuous increase in L-lysine dosage, the PWF and salt rejection started to decline.

The above results demonstrate that when the dosage of $\mathrm{L}^{-}$ lysine is $0.1 \mathrm{wt} \%$, the highest salt rejection is obtained, which suggests that the network structure of the polyamide TFC membrane is optimized at around this level. Furthermore, $R_{\mathrm{m}}$ can be used to understand the structural properties of the membranes. ${ }^{16}$ Fig. 10(a) shows the PWF of the polyamide TFC membranes under different feed pressures. $R_{\mathrm{m}}$ was calculated using the inverse of the slope of the PWF curves in Fig. 10(a), and the result of $R_{\mathrm{m}}$ is shown in Fig. 10(b). The lowest resistance value was obtained when the dosage of L-lysine was $0.1 \mathrm{wt} \%$, which suggests that the balance between the network structure, thickness and surface area is optimum at this point.

\subsection{Fouling experiments}

The anti-fouling properties of the TFC membranes were determined, and the results are shown in Fig. 11 and Table 5. Total flux decline ratio $\left(\mathrm{DR}_{\mathrm{t}}\right)$ and flux recovery ratio (FRR) are the two commonly used parameters to estimate the anti-fouling

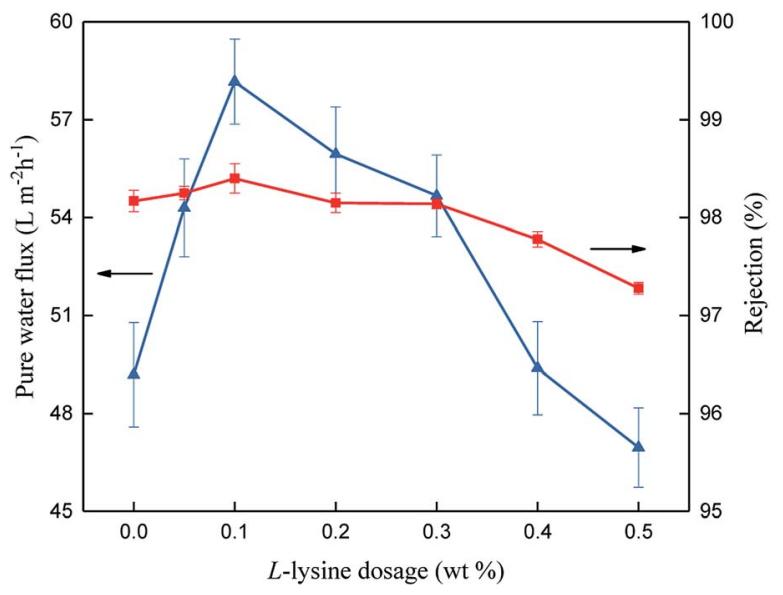

Fig. 9 Reverse osmosis performance of the TFC membranes. 

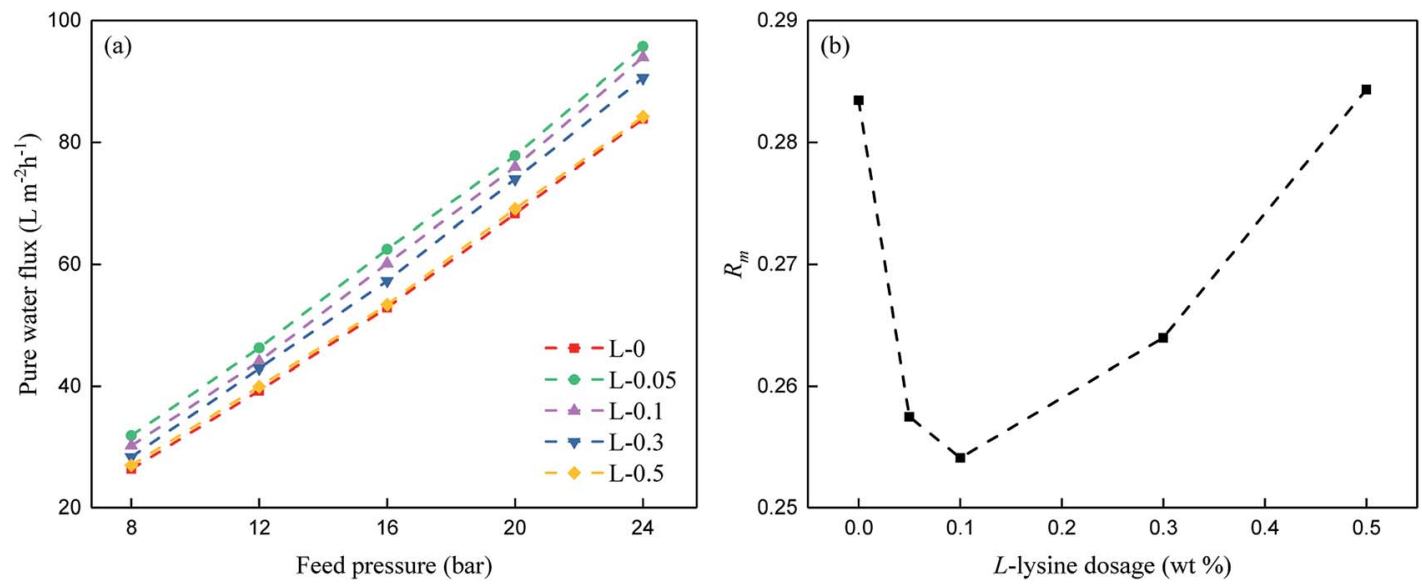

Fig. 10 (a) PWF of the polyamide TFC membranes at various feed pressures and (b) $R_{m}$ of the polyamide TFC membranes.

property of membranes. ${ }^{32,48} \mathrm{~A}$ higher FRR value and lower $\mathrm{DR}_{\mathrm{t}}$ value suggest better anti-fouling property.

From the data above, we can infer that after the introduction of $\mathrm{L}$-lysine, the $\mathrm{DR}_{\mathrm{t}}$ value decreases from $27.3 \%$ to $21.7 \%$ and the FRR value increases from $81.5 \%$ to $85.6 \%$, indicating the improvement in anti-fouling property of the membrane. Compared to the original TFC membranes, the TFC membranes with L-lysine are harder to foul and easier to recover. As mentioned above, grafting hydrophilic polymers onto the surface of TFC membranes can significantly increase their antifouling properties, but a decrease in flux cannot be avoided because of the resistance of the additional layer. However, the introduction of $\mathrm{L}$-lysine during the interfacial polymerization of the TFC membranes improved not only their water permeability and salt rejection, but also their fouling resistance.

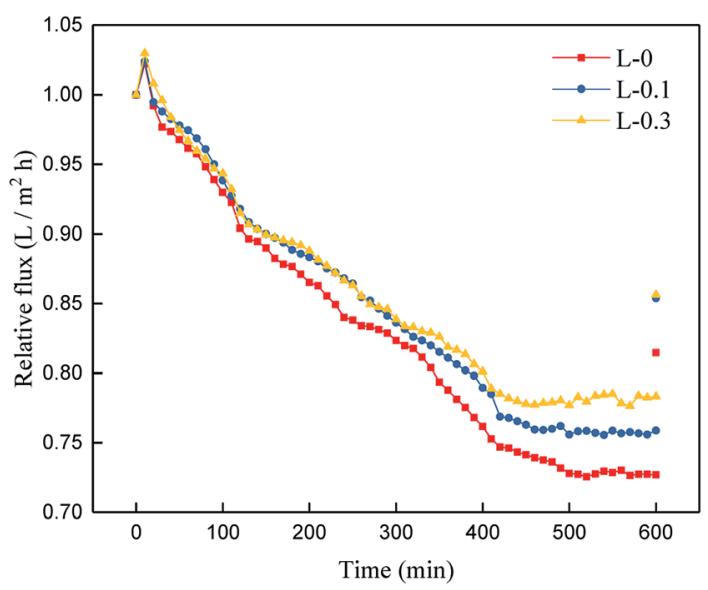

Fig. 11 Time-dependent relative flux of the TFC membranes (conducted with $500 \mathrm{mg} \mathrm{L}^{-1}$ colloidal silica).

Table 5 Anti-fouling parameters of the TFC membranes

\begin{tabular}{llll}
\hline & L-0 & L-0.1 & L-0.3 \\
\hline DR $_{\mathrm{t}}(\%)$ & $27.2 \pm 0.2$ & $24.2 \pm 0.1$ & $21.9 \pm 0.4$ \\
FRR (\%) & 81.5 & 85.4 & 85.6
\end{tabular}

Additionally, the low cost of L-lysine suggests that it is very promising for industrial applications.

\section{Discussion: the mechanism of $\mathrm{L}-$ lysine on the performances of the TFC membranes}

\subsection{Mechanism of ${ }_{L}$-lysine on the reverse osmosis performance}

In our research, reverse osmosis membranes were manufactured using the TFC method, and L-lysine was added to the aqueous solution as an additive. Subsequently, an improvement in flux in the RO membrane was observed. The results of ATRFTIR, SEM, AFM and contact angle tests show that the introduction of L-lysine during the interfacial polymerization significantly changes the morphology and structure of the polyamide membrane, resulting in a thinner and smoother membrane with better hydrophilic properties.

In detail, the diffusion rate of MPD in the MPD/L-lysine blend solution in hexane (organic phase) is slower than that of pure MPD, resulting in a reduction in the thickness of the polyamide selective layer. ${ }^{35}$ The reduction in the root-mean-square and surface area is surmised owing to the existence of a linear monomer; a previous study proved that linear monomers results in decreased roughness in the final membranes. ${ }^{49}$ The presence of carboxyl groups in the polyamide network may also contribute to the improvement in hydrophilicity due to the hydrogen bond interaction between the carboxyl group and water molecules. The surface charge of the polyamide selective layer is also affected by the carboxyl groups. The carboxyl groups in L-lysine led to the resulting polyamide showing a more negatively charged property.

Previous research has demonstrated that there are two types of sub-nanometer pores in the polyamide network: network pores and aggregate pores. ${ }^{23}$ The XPS result shows that the participation of L-lysine decreases the cross-linking degree of the polyamide matrix, which may occur because the backbone chain of L-lysine is more flexible than the aromatic structure in MPD. As a result, a looser thin polyamide selective layer with 


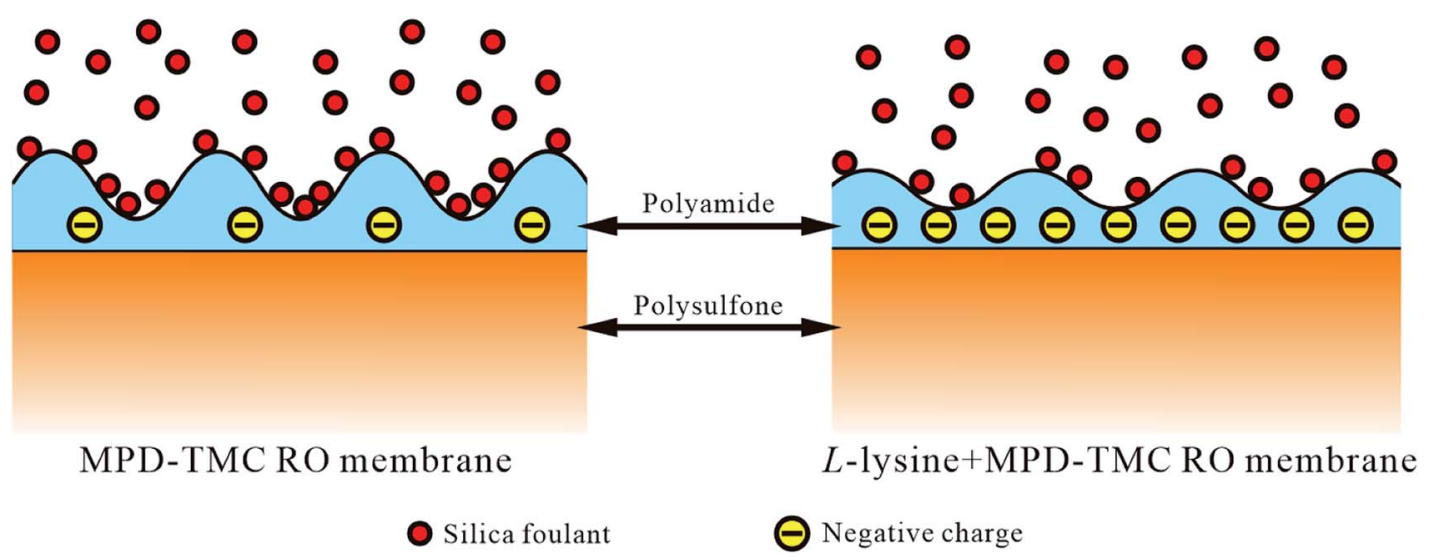

Fig. 12 Possible model of the anti-fouling property of the TFC membranes.

larger inner sub-nanometer pores and more free volume is expected.

Therefore, the phenomenon in which the PWF increases first and then decreases, as well as the decline in salt rejection with an increase in the dosage of L-lysine can be explained as follows. When the dosage of L-lysine is $0.05-0.1 \mathrm{wt} \%$, the thinner selective layer (increase in concentration gradient across the membrane ${ }^{2}$ ) with carboxyl groups (hydrogen bond interaction) as well as the loose structure (greater free volume and subnanometer pores) result in low hydraulic resistance to the permeability of the polyamide selective layer, ${ }^{50}$ which leads to an enhancement in PWF. Accordingly, an 18\% increase in flux is obtained when the dosage of L-lysine is $0.1 \mathrm{wt} \%$. When more $\mathrm{L}^{-}$ lysine is introduced, the selective layer becomes smoother and its surface area reduces significantly, resulting in less chance for the selective layer to contact with water molecules. The reduction in the surface area may have a major effect on the PWF and thus, the PWF is reduced with an increase in the dosage of L-lysine.

Simultaneously, a slight increase in salt rejection is observed when $0.1 \mathrm{wt} \%$ of $\mathrm{L}$-lysine is used, that is, less amount of L-lysine can increase the electric charge effect of the polyamide membrane, and weaken the salt permeation. ${ }^{31}$ However, a higher dosage of L-lysine may lead to the destruction of the tight structure of the aromatic polyamides and increase the electric charge effect. Therefore, a decrease in salt rejection cannot be avoided.

\subsection{Mechanism of $L$-lysine on the anti-fouling property}

According to the results in Sections 3.3 and 3.4, the enhanced anti-fouling property of the resulting membranes may be attributed to three aspects: ${ }^{25}$ (a) smoother surface, (b) higher hydrophilicity and (c) electrostatic repulsion.

In detail, first, the introduction of L-lysine decreases the surface roughness of the resulting membrane, and it is difficult for colloidal particles to accumulate at the valleys of the membrane surface. Second, the higher hydrophilicity leads to better anti-fouling property because the foulants are hydrophobic. Thirdly, it is universally accepted that repulsive forces provide bonus fouling resistance between colloidal foulants and the charged surface of membranes because the colloidal silica and carboxyl groups in L-lysine show the same negative charges. Thus, the deposition of colloidal silica on the surface of the membrane becomes harder, which reduces the fouling. ${ }^{25}$ The possible model of the anti-fouling property of the TFC membranes is presented in Fig. 12.

\section{Conclusion}

In this study, MPD and TMC were selected as the aqueous monomer and organic monomer, respectively, to manufacture reverse osmosis TFC membranes. L-Lysine was added to the aqueous solution as an additive during interfacial polymerization. Furthermore, the impact of L-lysine on the morphology and properties of the TFC membrane was carefully investigated.

The results show that as the dosage of L-lysine in MPD increases, the polyamide selective layer becomes smoother and thinner, and its surface area and contact angle are reduced. The RO performance of the TFC membranes shows that the addition of L-lysine into MPD/TMC polyamide membranes significantly enhances their practical performances as well as surface properties and chemical structures. The PWF of the polyamide membrane increased to $58.17 \mathrm{~L}\left(\mathrm{~m}^{-2} \mathrm{~h}^{-1}\right)$ compared with the original $49.19 \mathrm{~L}\left(\mathrm{~m}^{-2} \mathrm{~h}^{-1}\right)$, and had an $18 \%$ increase after $0.1 \mathrm{wt} \%$ of L-lysine was introduced. In addition, the salt rejection slightly increased from the original $98.17 \%$ to $98.40 \%$. From the anti-fouling experiments, the increase in FRR value and decrease in $\mathrm{DR}_{\mathrm{t}}$ value suggest that the anti-fouling property of the membranes was enhanced after the introduction of L-lysine.

\section{Conflicts of interest}

There are no conflicts to declare.

\section{Acknowledgements}

We gratefully acknowledge the National Science Foundation of China (NSFC 51503134, 51421061, 51721091) and the State Key Laboratory of Polymer Materials Engineering (Grant No. SKLPME 2017-3-02) for the financial support. 


\section{References}

1 C. Reid and E. Breton, Water and ion flow across cellulosic membranes, J. Appl. Polym. Sci., 1959, 1(2), 133-143.

2 R. W. Baker, Membrane technology and applications, John Wiley \& Sons, Ltd, 2004, pp. 96-103.

3 J. Cadotte, R. Petersen, R. Larson and E. Erickson, A new thin-film composite seawater reverse osmosis membrane, Desalination, 1980, 32, 25-31.

4 T. Ikeda, H. Muragishi, R. Bairinji and T. Uemura, Advanced reverse osmosis membrane modules for novel ultrapure water production process, Desalination, 1994, 98(1-3), 391400.

5 M. Kurihara, Y. Fusaoka, T. Sasaki, R. Bairinji and T. Uemura, Development of crosslinked fully aromatic polyamide ultra-thin composite membranes for seawater desalination, Desalination, 1994, 96(1-3), 133-143.

6 C. Das, P. Patel, S. De and S. DasGupta, Treatment of tanning effluent using nanofiltration followed by reverse osmosis, Sep. Purif. Technol., 2006, 50(3), 291-299.

7 A. M'nif, S. Bouguecha, B. Hamrouni and M. Dhahbi, Coupling of membrane processes for brackish water desalination, Desalination, 2007, 203(1-3), 331-336.

8 A. D. Khawaji, I. K. Kutubkhanah and J.-M. Wie, Advances in seawater desalination technologies, Desalination, 2008, 221(1-3), 47-69.

9 H. Zhang, S. Fang, C. Ye, M. Wang, H. Cheng, H. Wen and $\mathrm{X}$. Meng, Treatment of waste filature oil/water emulsion by combined demulsification and reverse osmosis, Sep. Purif. Technol., 2008, 63(2), 264-268.

10 L.-F. Liu, L.-L. Yang, K.-Y. Jin, D.-Q. Xu and C.-J. Gao, Recovery of L-tryptophan from crystallization wastewater by combined membrane process, Sep. Purif. Technol., 2009, 66(3), 443-449.

11 M. J. López-Muñoz, J. M. Arsuaga and A. Sotto, Separation of phenols and their advanced oxidation intermediate products in aqueous solution by NF/RO membranes, Sep. Purif. Technol., 2010, 71(2), 246-251.

12 R. J. Petersen, Composite reverse osmosis and nanofiltration membranes, J. Membr. Sci., 1993, 83(1), 81-150.

13 S.-Y. Kwak, M.-O. Yeom, I. J. Roh, D. Y. Kim and J.-J. Kim, Correlations of chemical structure, atomic force microscopy (AFM) morphology, and reverse osmosis (RO) characteristics in aromatic polyester high-flux RO membranes, J. Membr. Sci., 1997, 132(2), 183-191.

14 L.-F. Liu, S.-C. Yu, Y. Zhou and C.-J. Gao, Study on a novel polyamide-urea reverse osmosis composite membrane (ICIC-MPD): I. Preparation and characterization of ICICMPD membrane, J. Membr. Sci., 2006, 281(1), 88-94.

15 T. Matsuura, Progress in membrane science and technology for seawater desalination-a review, Desalination, 2001, 134(1-3), 47-54.

16 D. H. N. Perera, Q. Song, H. Qiblawey and E. Sivaniah, Regulating the aqueous phase monomer balance for flux improvement in polyamide thin film composite membranes, J. Membr. Sci., 2015, 487, 74-82.
17 Z. Yong, Y. Sanchuan, L. Meihong and G. Congjie, Polyamide thin film composite membrane prepared from $\mathrm{m}^{-}$ phenylenediamine and $m$-phenylenediamine-5-sulfonic acid, J. Membr. Sci., 2006, 270(1), 162-168.

18 H. Wang, L. Li, X. Zhang and S. Zhang, Polyamide thin-film composite membranes prepared from a novel triamine 3, 5diamino- $N$-(4-aminophenyl)-benzamide monomer and $m$ phenylenediamine, J. Membr. Sci., 2010, 353(1), 78-84.

19 M. A. Seman, M. Khayet and N. Hilal, Nanofiltration thinfilm composite polyester polyethersulfone-based membranes prepared by interfacial polymerization, $J$. Membr. Sci., 2010, 348(1), 109-116.

20 A. Ahmad, B. Ooi and J. Choudhury, Preparation and characterization of co-polyamide thin film composite membrane from piperazine and 3,5-diaminobenzoic acid, Desalination, 2003, 158(1-3), 101-108.

$21 \mathrm{~J}$. E. Cadotte, Alkali resistant hyperfiltration membrane, US Pat. 4895661, 1990.

22 P. G. Ingole, K. Singh and H. Bajaj, Optical resolution of alpha-amino acid derivative through membrane process, Indian J. Chem. Technol., 2011, 18(3), 197-206.

23 S. H. Kim, S. Y. Kwak and T. Suzuki, Positron annihilation spectroscopic evidence to demonstrate the fluxenhancement mechanism in morphology-controlled thinfilm-composite (TFC) membrane, Environ. Sci. Technol., 2005, 39(6), 1764.

24 G. Kang, M. Liu, B. Lin, Y. Cao and Q. Yuan, A novel method of surface modification on thin-film composite reverse osmosis membrane by grafting poly(ethylene glycol), Polymer, 2007, 48(5), 1165-1170.

25 D. Rana and T. Matsuura, Surface modifications for antifouling membranes, Chem. Rev., 2010, 110(4), 24482471.

26 K. Singh, P. G. Ingole, J. Chaudhari, H. Bhrambhatt, A. Bhattacharya and H. C. Bajaj, Resolution of racemic mixture of $\alpha$-amino acid derivative through composite membrane, J. Membr. Sci., 2011, 378(1), 531-540.

27 V. Freger, Nanoscale heterogeneity of polyamide membranes formed by interfacial polymerization, Langmuir, 2003, 19(11), 4791-4797.

28 J. N. Weinstein, B. J. Bunow and S. R. Caplan, Transport properties of charge-mosaic membranes I. Theoretical models, Desalination, 1972, 11(3), 341-377.

29 J. N. Weinstein, B. M. Misra, D. Kalif and S. R. Caplan, Transport properties of charge-mosaic membranes II. Experimental studies, Desalination, 1973, 12(1), 1-17.

30 C. R. Gardner, J. N. Weinstein and S. R. Caplan, Transport properties of charge-mosaic membranes III. Piezodialysis, Desalination, 1973, 12(1), 19-33.

31 J. Wang, Y. Zhang, J. Zhu, J. Hou, J. Liu and B. Van der Bruggen, Zwitterionic functionalized layered double hydroxides nanosheets for a novel charged mosaic membrane with high salt permeability, J. Membr. Sci., 2016, 510, 27-37.

32 L. Fan, Q. Zhang, Z. Yang, R. Zhang, Y. N. Liu, M. He, Z. Jiang and $\mathrm{Y}$. Su, Improving permeation and antifouling performance of the polyamide nanofiltration membrane 
through incorporating arginine, ACS Appl. Mater. Interfaces, 2017, 9(15).

33 K. Scott, Handbook of industrial membranes, Elsevier, 1995.

34 N. N. Li, M. A. Kuehne and R. J. Petersen, High flux reverse osmosis membrane, US Pat. 6162358, 2000.

35 M. Duan, Z. Wang, J. Xu, J. Wang and S. Wang, Influence of hexamethyl phosphoramide on polyamide composite reverse osmosis membrane performance, Sep. Purif. Technol., 2010, 75(2), 145-155.

36 J. Wang, R. Xu, F. Yang, J. Kang, Y. Cao and M. Xiang, Probing influences of support layer on the morphology of polyamide selective layer of thin film composite membrane, J. Membr. Sci., 2018.

37 G. N. B. Baroña, J. Lim and B. Jung, High performance thin film composite polyamide reverse osmosis membrane prepared via $m$-phenylenediamine and 2,2'benzidinedisulfonic acid, Desalination, 2012, 291, 69-77.

38 R. N. Wenzel, Surface Roughness and Contact Angle, J. Phys. Colloid Chem., 1949, 53(9), 1466-1467.

39 S. Zhu, S. Zhao, Z. Wang, X. Tian, M. Shi, J. Wang and S. Wang, Improved performance of polyamide thin-film composite nanofiltration membrane by using polyetersulfone/polyaniline membrane as the substrate, $J$. Membr. Sci., 2015, 493, 263-274.

$40 \mathrm{Y}$. Jin and Z. Su, Effects of polymerization conditions on hydrophilic groups in aromatic polyamide thin films, $J$. Membr. Sci., 2009, 330(1), 175-179.

41 Y. Song, P. Sun, L. L. Henry and B. Sun, Mechanisms of structure and performance controlled thin film composite membrane formation via interfacial polymerization process, J. Membr. Sci., 2005, 251(1), 67-79.

42 J. Kucera, Reverse osmosis: design, processes, and applications for engineers, Scrivener Pub, 2010.
43 W. J. Lau, A. F. Ismail, N. Misdan and M. A. Kassim, A recent progress in thin film composite membrane: A review, Desalination, 2012, 287(3), 190-199.

44 H. Wang, L. Li, X. Zhang and S. Zhang, Polyamide thin-film composite membranes prepared from a novel triamine 3,5diamino- $N$-(4-aminophenyl)-benzamide monomer and $\mathrm{m}$ phenylenediamine, J. Membr. Sci., 2010, 353(1), 78-84.

45 M. L. Lind, D. E. Suk, T. V. Nguyen and E. M. V. Hoek, Tailoring the Structure of Thin Film Nanocomposite Membranes to Achieve Seawater RO Membrane Performance, Environ. Sci. Technol., 2010, 44(21), 8230.

46 A. Marmur, Wetting on Hydrophobic Rough Surfaces: To Be Heterogeneous or Not To Be?, Langmuir, 2003, 19(20), 83438348.

47 M. Liu, Q. Chen, L. Wang, S. Yu and C. Gao, Improving fouling resistance and chlorine stability of aromatic polyamide thin-film composite RO membrane by surface grafting of polyvinyl alcohol (PVA), Desalination, 2015, 367, 11-20.

48 T. Ma, Y. Su, Y. Li, R. Zhang, Y. Liu, M. He, Y. Li, N. Dong, $\mathrm{H}$. $\mathrm{Wu}$ and $\mathrm{Z}$. Jiang, Fabrication of electro-neutral nanofiltration membranes at neutral $\mathrm{pH}$ with antifouling surface via interfacial polymerization from a novel zwitterionic amine monomer, J. Membr. Sci., 2016, 503, 101-109.

49 Y. H. Huang, W. C. Chao, W. S. Hung, Q. F. An, K. S. Chang, S. H. Huang, K. L. Tung, K. R. Lee and J. Y. Lai, Investigation of fine-structure of polyamide thin-film composite membrane under swelling effect by positron annihilation lifetime spectroscopy and molecular dynamics simulation, J. Membr. Sci., 2012, 417-418(s 417-418), 201-209.

50 E. P. Chan, A. P. Young, J. H. Lee and C. M. Stafford, Swelling of Ultrathin Molecular Layer-by-Layer Polyamide Water Desalination Membranes, J. Polym. Sci., Part B: Polym. Phys., 2014, 10(17), 2949. 